\title{
Effective Environmental Management: A Panacea for Socio-Economic Development of Developing Countries
}

\author{
Uwakwe Felicia E.
}

\author{
Department of Biotechnology, \\ Federal University of Technology, Owerri, Nigeria
}

Kamalu Nkeiru A.

Department of Animal and Environmental Biology

Imo State University, Owerri, Nigeria

\section{Doi:10.5901/ajis.2013.v2n6p175}

\begin{abstract}
The science of environmental management is one of the areas of great interest in the present millennium. It deals with the whole concept of the environment, its characteristics, resources, and effective exploitation for the benefit of man. The environment offers unlimited opportunities for socio-economic development through effective exploration and exploitation of the available resources and purposeful utilization of the proceeds in developmental projects. However, in developing countries, environmental management is subject to various limitation and draw backs. Consequently these countries continues to grapple with the challenges of climate change and its impacts, food security, population explosion, pest infestation, communicablediseases as well as pollution, contamination and environmental sustainability. The overall effects are poverty, low living standard, poor health, inadequate housing, high level of unemployment and underemployment, low agricultural productivity, technological backwardness and poor socio-economic development. Against the above background, it becomes pertinent to carry out an investigation on the essence and methods of effective environmental management, its socio-economic implications and the problems militating effective utilization of environmental resources in developing countries, hence this research. The work is a descriptive survey and the investigation revealed that lack of knowledge and proper planning in environmental issues, lack of executive capacity, technical know-how and political will as well as inadequate funding and socio-cultural inclinations are some of the factors limiting effective environmental management in developing countries. It is therefore recommended that adequate budgetary provisions be made for funding research on environmental management, capacity building and human development.
\end{abstract}

Keywords: Environmental management, exploitation, natural resources, sustainability, socioeconomic development.

\section{Introduction}

The United Nations system did not stipulate any established convention for the designation of developed and developing countries or areas. According to the United Nation's statistics division, the development of any country is measured with statistical indices such as human development, income per capital, life expectancy, the rate of literacy (education) and the provision of adequate public and health care services. A developing country is a country that is poor, and whose citizens are mostly agricultural workers, but want to become more 
advanced socially and economically (Wikipedia, 2013). Development can also be perceived in terms of industrial and technological advancement of a country. Based on this perspective, Sullivan and Stephen (2003) viewed a developing country as a less-developed nation with a low living standard, under-developed industrial base and low human development index (HDI) relative to other countries. According to them, these countries have not achieved significant degree of industrialization relative to their populations, human development, effective health care delivery and have in most cases a low per capita income.

Generally, developing countries are characterized by wide spread poverty associated with low income, inadequate housing, poor health, and inadequate or non-existent public health services. Other features as reported by Kintu (2008) include limited or no education, substantial dependence on agricultural produce with low productivity, high and rising levels of unemployment, dualistic economy and technological backwardness. Furthermore, Wikipedia (2013) identified other features as very high population rate, shorter life expectancy of 51 years as compared with 75 years for developed countries, which translates to smaller percentage of the population being available for labour. Consequently, they are barely able to satisfy their basic needs, working long hours and earning little. This is as a result of inadequate job opportunities, skills, tools and machines, and the use of primitive technology, poor organization and limited physical and human capital inputs.

The economy of any country revolves on the environment. Adequate knowledge of the environment, its available and potential resources and the purposeful exploitation and utilization of the proceeds in areas of developmental projects like road construction building of schools and hospitals and the installation of others essential public and social welfare projects can bring rapid transformation of the economy of any country. These potential available in the environment can be harnessed through the establishment of an effective environmental management system which is based on certain principles such as proper understanding of the ecology and accurate documentation of environmental resources, purposeful exploitation and gainful deployment of proceeds, improvement on environmental setting, focus on environmental problems and protection and conservation of resources. In most developing countries, environmental issues are not given adequate and appropriate attention resulting to the under-development of environment-related projects and under-utilization of environmental resources. Effective management of the three categories of environment improves food security, provide substantial income through commercial sale of products as well as provides opportunities for employment and community self-reliance projects. The over all effect would be the attainment of socio-economic growth and sustainable development, in a pristine, healthy, supportive and sustainable environment.

\subsection{The Nature of the environment}

In the simplest form, the environment is reckoned with as the immediate surrounding and outline areas of an individual. However the environment in the wide sense may be conceptualized to comprise the entire globe or earth and the outer space which affects life on earth. The environment consists basically of biotic and abiotic components. The biotic components comprise all life forms which include a wide range of plants, animals and microorganisms. On the other hand, the abiotic components encompass all the non-living materials which include among others, the soil, water, rocks, organic and inorganic substances. The part of the earth which supports life is known as the biosphere, while the non-living earth crust is called the lithosphere. The major part of the earth is covered with water and this forms the hydrosphere which houses a wide range of life forms. 
The environment is divided into different geographical regions, within which are various ecological zones. Within the zones exist various types of habits, micro-habitats and ecological niches habouring different types of living things. Man's environment according to Lucas and Gilles (1990) consists of three major components: physical, biological and social. The physical environment refers to the non factor like air, soil, water, minerals and climatic factors which have direct effects on man, his comfort and performance. The physical environment also affects the distribution of organisms like plants that provide man with food, shelter and clothing, animals that compete with him and vectors that produce and transmit diseases. The biological environment on the other hand comprises all living things which are dependent on each another and their physical environment, while the social environment deals with man and his society. In other words, the environment has a profound influence on man, and at the same time, man extensively alters the environment to suit his needs and desires (Lucas and Giles, 1990)

The environment is subject to natural influences such as earthquake, thunderstorms, volcanic eruptions, hurricanes, tornadoes, erosion, flooding as well as climatic factors like sunshine, temperature and humidity. Added to these are all forms of interactions between the biotic and abiotic components and various anthropologenic activities. The environment is therefore not static, but dynamic and these fluctuations usually have severe impacts on the quality of the environment, and the survival of man and other life forms.

\section{The Concept of Environmental Management}

Environmental management is one of the areas of great interest in the present millennium. It deals with the whole concept of the environment, its characteristics, exploitation and management to achieve environmental sustainability, security and continuity of life on earth. Environmental management therefore focuses on various habitats, their natural resources including available life forms, the nature of biodiversity in a given area and other non - living environmental resources, and how best all these potentials could be exploited and harnessed for the benefit of man and other life forms. The multiplicity of species of organisms in various environments, and their diverse nature, ecological spread and natural histories form the basis of the modern concept of biodiversity (I wuala, 2012). The importance of biological diversity to human society, according to United Nations Environment Programme (UNEP, 2010) is hard to over state. It is estimated that $40 \%$ of the global economy is based on biological products and processes and besides living things, there are other vital environmental resources of great value to the economy of any state or country (Iwuala, 2012). Environmental management offers mankind the opportunity to maximize the benefits of these resources to achieve sustainability and economic growth.

Environmental management was viewed by Pahl-Most (2006) in terms of resource management and described as a purposeful activity with the goal to maintain and improve the state of environmental resources affected by human activities. He further pointed out that environmental resource management aims at ensuring that ecosystem service are protected an maintained for equitable use by future human generations, and at the same time maintaining ecosystem integrity by taking into consideration ethnical, economic and scientific variables. Furthermore, environmental management takes into consideration all components of the environment, living (biotic) and non -living (abiotic) and also the relationship of the human environment such as social, cultural, economic and bio-physical (Colby, 1991). Commenting on the goals of environmental management, Wikipedia (2012) enumerated the following: reduction and cleaning up all sorts of pollution with the future goal of zero pollution, emphasis on clean and alternative energy sources that have low carbon emission, sustainable use of water, land and other scare resources, preservation of existing endangered species and protection of biodiversity. 
Virtually, all sectors of the economy of any country depend essentially on the environment and its resources. The overall essence of environmental management is therefore to help man explore and exploit the natural and human resources available in the environment and deploy the proceeds effectively for improve living conditions, better longevity and socio-economic development, while at the same time maintain the quality of the environment.

Generally, the environment is saddled with problems which Adeoti (2012) identified as loss of soil fertility, desertification, hazardous wastes in natural media and loss of biodiversity. Other problems to content with include pollution, climate change, global warming, rise in sea water, population explosion, natural disasters, acid rain and other ecological problems. These problems impact on humans and other life forms and could be taken care of through effective management of the environment.

\section{Management of Various Types of Environments}

In Environmental Management, three broad categories of environment are distinguished and these include terrestrial (land) aquatic(water) and aerial (air) environments or habitats. Terrestrial environment constitutes a significant portion of the earth and habours the entire soil, rocks and the covering vegetation. It also sustains animal settlements and holds substantial mineral and metallic resources. In addition, terrestrial environment supports the establishments of human settlements and urban cities, semi-urban towns and rural communities. The ecological characteristics of terrestrial environment differs from community to community, and from town to town in terms of animal population, nature of vegetation, occurrence of inland water bodies, soil, climate factors and other ecological indices.

In contrast, aquatic environment consists of natural water bodies which generally belong to two broad categories; marine environment and freshwater environment. The marine environment comprises salt water bodies which include the oceans and seas. These are large water babies with great volume, depth and cover a verse expanse of space. On the other hand, freshwater bodies include rivers, stream, ponds, lakes which are salt-free and sources of portable water. The water bodies are smaller then marine in terms of water depth, volume, circumference and space. The aquatic environments harbour substantial quantity of plant and animal populations and mineral resources.

Aerial environment comprises the entire gaseous atmosphere above the land and water as well as within houses, homes and other enclosures. The aerial environment has a perculiar physical form and is subject to contamination, physical phenomena and physical factors like wind movement, temperature fluctuations, humidity changes, percolation of water, gravity, light and heat transmission and movement of sounds. Like the terrestrial and aquatic environments, aerial environment harburs various life forms

The task of managing specific types of environment is usually guided by the nature and characteristics of such environments. In the management of the three types of environment therefore, we reckoned with a wide range of measures, strategies and operations, all designed to understand the nature of such environments, exploit the available resources and maximize the use of the proceeds in development and conservation of the natural environments for future beneficial uses. The methods commonly employed in the management of the different types of environments consists of the following:

\subsection{Adequate knowledge and proper understanding of the particular environment}

This requires indepth knowledge and first hand information about the particular environment under study. Such information as the geographical location, territorial space, physical characteristics, the 
ecology of the various habitats and niches, plus the animal and plant populations and their distribution patterns are of great importance. Furthermore, the available natural resources, the inter-relationship of the biotic and abiotic components and the prevailing climate, natural and anthropogenic influences should be properly documented. Detailed information on these various indices need to be collated and analyzed for meaningful assessment of the environment.

\subsection{Environmental planning}

Effective planning for management of the environment will require adequate data on household, animal and plant settlements, land utilization, rural and urban planning, delineation of roads and other infrastructure and supervised implementation of environmental layout programmes. The planning should also take account of the available resources, their potential values and possible exploitation for economic benefit. Environmental beautification and estate management may also be considered as part of the initial programme for effective management of the environment.

\subsection{Effective waste management and disposal}

Effective waste management constitutes another important approach to effective management of various environments. This is because all living organisms, as part of their normal life activities generate and exude various forms of wastes on a daily basis. In addition, every activity of man leads to the generation of wastes, some of which are hazardous and cause danger to humans, other life forms and degrade the environment. Accumulation of refuse in the environment leads to the pollution of land, air and water, thereby increasing the likelihood of the spread and transmission of air -borne and water - related diseases (Uwakwe and I wuala, 2012). For effective waste management and disposal, we require proper knowledge and classification of the different waste types generated, identification of collection centres and the employment of reliable waste collection and disposal strategies. There is also the need to define waste dumping and elimination sites and regular evacuation practices to avoid accumulation. Proper waste management is a step toward sustainable development since waste treatment and disposal occur in such a manner as to render them harmless to humans, other life forms, the economy and the environment (Adewole, 2009).

\subsection{Active pollution management and control}

Active pollution management aims at sanitizing the environment and protecting life and life forms. The emphasis here is on safe elimination and prevention of contamination and damage due to poison chemicals, irradiation agents and other forms of toxic hazards that may feature in the environment. This strategy would attempt to understand, defined and categorize different types of pollution and pollution agents as well as evolve techniques for detection, investigation and handling the various case of pollution available in respective environments.

\subsection{Effective disease prevention and control}

This aspect of environmental management is fundamental to the preservation and prolongation of life. Diseases may result from unhealthy exposure to various microbes, dangerous chemicals, gases, irradiations and dusts. Measures employed would include putting facilities in place for disease documentation, treatment, prevention and surveillance. In addition, efforts should be geared toward the control and destruction of disease vectors and other harmful agents that may be involved in the dissemination and sustenance of infections. 


\subsection{Effective Pest Management and control}

This aspect deals with the regulation of different types of pests that feature in different environments. For example, various forms of household, medical, agricultural, industrial, forestry and wildlife pests as well as cosmopolitan pests found in different habitats and niches of the globe. Pests account for far-reaching loses of life and properties, destruction of agricultural produce, drastic drainage in the economy and destruction of wood work, furniture and various household properties. It is therefore obvious that in managing the environment, pests constitute a factor to be reckoned with. Handlings pests involves the development and employment of different methods of pest control and regulation, taking into account the characteristics of the environment under study.

\subsection{Economic management of land resources}

This is a strategic method of managing terrestrial environment. Here all resources on land are taken into account, including human, animals, plant, minerals and other economic resources. Proper utilization of the soil and land resources for agriculture, town and rural development, installation of infrastructure like roads, schools, hospitals and other public utilities constitute parts of the management of land resources. Added to these is the establishment of forestry and wildlife reserves, and other agricultural enterprises like livestock rearing, poultry farming and other forms of animal husbandry. Development of land resources and the exploitation of such resource lead to revenue generation, investment, development of communities and socio-economic growth.

\subsection{Economic management of water resource}

In dealing with the management of water resources, we reckon with such reforms as management of river basins, coastal maintenance and dredging of various water bodies, drainage, irrigation and creation of dams for agricultural, commercial and industrial purposes and maritime uses. Furthermore, fish farming, aquaculture and installation of processing facilities for the exploitation of aquatic organisms like prawn, crabs, fingerlings and other forms of sea food are encouraged as comprehensive management of water resources. Processing and reticulation of water for domestic and industrial uses, and under water exploration and exploitation of mineral resources are also considered as parts of management of water resources. It is the belief that the bulk of animals to provide sustenance for humans may be found in the seas and oceans and countries that are dependent on exploitation of marine and sea food usually have viable economies and adequate nutritional supplies(Uwakwe and Ehujuo, 2012).

\subsection{Economic management of aerial resources}

In this approach of environmental management, the procedures include meteorological studies and monitoring of the atmosphere, planning and regulation of canopies, shades and shelters, establishment and maintenance of airway and air transportation services and socio-economic uses of air space and atmospheric resources. Space control is also considered in town planning for allocation of sites for high - rise buildings, small structures and recreational facilities. specific tariffs and other charges may be imposed for use of aerial spaces and the revenue generated employed for developmental projects. 


\subsection{Environmental Regulation, Protection and Conservation}

Environmental regulation and protection for healthy sustenance of life and life forms focuses on the need for ecological checks and balances to ensure proper protection and conservation of humans and other organisms. To this end, proper environmental laws, edicts and decrees need to be enacted and enforced on citizens to ensure compliances. Such laws include for example public health bye-law on sanitation, vaccination of infants, establishment of markets, arbatoirs, manufacturing units, and laws regulating the handling of pesticides, agro-chemicals and other dangerous chemicals. Similarly, various forms of environmental regulation covering conservation of wildlife, establishment of forest reserves, rural and urban layouts, recreational centres and excavation need to be put in place for effective conservation of environmental aesthetics.

\subsection{Manpower Training and Development}

This aspect of environmental management is concerned with human resources development for effective environmental management services. It requires detailed appraisal of the scope of personnel required for the management of any given environment. As a part of planning in various countries and states, basic education of human population is considered a fundamental right for children and adolescents. This strategy enhances literacy levels and guarantees improved quality of life for the human population. It also calls for periodic training, job orientation and seminars or workshops for both the senior and juniors cadres of staff including the unskilled and semi-skilled personnel needed for field operations in areas of waste management pollution and pest control, agriculture and forestry services, urban and rural maintenance services, water supply, sanitation and various aspects of environmental management services. Furthermore, capacity building programmes should be organized for the expert cadres which include top personnel architects, economists, planners, agricultural and industrial personnels, health personnels, engineers, quantity surveyors, hydro geologists and various other experts that may be needed for the different operations under a strategic environmental management programme.

\subsection{Public Enlightenment and Health Education}

This approach is quite essential to achieve effective environmental management. This is because the general public is entitled to know and appreciate the significance of environmental management programmes which affect them. It become pertinent to involved the wider community in various aspects of environmental management efforts such as measures targeted at waste management and disposal, pollution control, disease prevention and control, mineral exploration and exploitation and development of agricultural practices. This can be achieved through public enlightenment and health education using the electronic media, newspaper, magazines, fliers, gingles. Awareness programmes can also be carried out through Institutions, town unions, market associations and other pressure groups. Through enlightenment the general public would become aware of the various potentials and opportunities offered by the different environments, and work towards exploiting and harnessing them for improved living standards and socio-economic development.

\section{Socio-Economic Importance of Effective Environmental Management}

In practice, it is pertinent to note that virtually all sectors of the economy of any country depend essentially on the environment and its available resources and opportunities. Effective management of the different categories of the environment offers great advantages with respect to gainful 
exploitation of natural and human resources and minimization of environmental loses and spoilage through control of pollution disease contamination wastes and pest infestations. Environmental management aims at achieving environmental sustainability which according to I wuala (2012) is the guiding principles for a green economy that focuses on maximizing the use of natural resources in the environment to achieve a healthy, sanitary and supportive environment for man and other life forms. Furthermore, effective management of the environment is the main thrust in the establishment of various groups and organizations which form the framework that helps to achieve environmental goals through consistent polices and control measures for maintaining a healthy and sanitary environment internationally and locally (UNEP, 2010). Such groups include World health Organization (WHO), United nations Environment Programe (UNEP), United Nations Development Programme (UNDP), Food and Agricultural Organization (FAO), Environmental management System (SME), United nations population Council (UNPC) as well as various professional bodies. These organizations have been working in an integrated manner to achieve health care, adequate food supply, population regulation and environmental improvement through flood control, pest management, irrigation activities and other environmental manipulation services to checkmate the impacts of natural disasters in the globe (I wuala, 2012).

The overall socio-economic importance of environmental management include among others the following:

- Achievement of environmental sanitation and protection and consequent reduction in the spread and sustenance of diseases, pollution and contamination.

- Establishment of improved health care and social welfare services.

- Development of viable and integrated agricultural practices which guarantee food security and exportation.

- Effective exploitation of minerals and other natural resources including sand, metallic ores, oil and gas.

- Improved literacy level through human development and capacity building.

- Effective use of land, aquatic and air spaces for economic development.

- Establishment of industries and creation of job opportunities.

- Technological development

- Environmental beautification and aesthetics.

- The practice of environmental impact assessment to protect humans and other life forms from adverse effects of developmental projects.

- Achievement of environmental protection, preservation and conservation to prevent wastage, spoilage and extinction of species.

- Increased substantial revenue, improved living conditions and prolonged longevity.

- Attainment of environmental sustainability, sustainable and socio-economic development.

\section{Problems and Limitations of Environmental Management in Developing Countries}

In most developing countries of the world, environmental management practices suffer various draw-backs which result to deficiency in the level of success achieved in the environmental management issues. Consequently, these countries are saddled with the problem of poverty, unemployment, low standard of living and poor technological and industrial development. The limitations to effective environmental management could be traceable to some fundamental issues which include;

- Limited public enlightenment and involvement in the practice of environmental management.

- Lack of adequate knowledge, understanding and appreciation of the essence of environmental management. 
- Lack of executive capacity and technical know-how.

- Lack of political will and commitment in dealing with environmental management challenges.

- Poor funding and inadequate capital involvement in environmental management programs.

- lack of proper planning and projections in dealing with environmental management issues.

- Natural ecology, seasonal factors and climatic fluctuations.

- Cultural belief and inclinations

\section{Recommendations}

The knowledge and practice of effective environmental management offer a lot of opportunities for economic development of any country. To be able to harness these opportunities, the following recommendations are made to developing countries;

1. That adequate budgetary provision be made for environmental management studies.

2. That experts in environmental management be employed and sustained for development of programs pertaining to effective handling of environmental issues.

3. That capacity building programmes for human development in areas of environmental management be organized and sustained.

4. That public enlightenment campaign be organized to educate the public on the practice and essence of environmental management, and the consequences of degradation and ineffective management of the environment.

\section{Conclusion}

Effective environmental management practices provide ways of protecting the environment and harnessing the unlimited resources available in the environment. Developing countries have not been able to effectively explore and exploit the environmental resources due to limited funding, lack of knowledge and the lack of commitment by the government and people in dealing with environmental issues. A progressive and knowledge driven economy may be built on proper understanding of our environment and the purposeful exploitation of the facilities offered by the environment for improved living conditions, better longevity and more productive agricultural and industrial activities. Consequently, the environment becomes sustainable and enhances the achievement of green economy and sustainable development. Effective management of the environment is therefore a panacea for socio-economic development in developing countries.

\section{References}

Adeoti, J. O. (2012) Technological Issues in Environmental Management in a Late Industrializer. Nigerian Institute of Social and Economic Research (NISER). I badan, Nigeria.

Adewole, A.T. (209) Waste management towards Sustainable Development in Nigeria: A case study of Lagos State. International NGO J ournal. Vo. 4(4) pp. 173-179.

Colby, M.E. (1991) Environmental Management in Development. The Evolution of Paradigms. Ecological Economics. Vol. 3 pp193-213.

I wuala, M.O. (2012) Green Economy: The Practical Implications. A Paper presented at the 2012 World Environment Day. Owerri, Nigeria 2012.

Kintu, A.B. (2008) Characteristics of Developing Countries. www.shoong.com

Lucas, A.O. and Gilles, H.M (1990) A Short Textbook of Preventive Medicine for the Tropic. ELBS Edward Arnold Publishers. Dunton Green, Kent. 
Pahl- Wost, C. (2006) The Implications of Complexity for Integrated Resource Management. Environmental Modelling and software. 22 (2007) pp. 561-569.

Sullivan, A and Stephen, M.S (2003) Economics: Principles in Action. Pearson Prentice hall. New Jersey.

UNEP (2010) A brief for Policy Makers on the Green Economy and Millennium Development Goals. $\mathrm{Htt}: / /$ www.unep.org/greeneconomy/portals/30.

UNEP (2010) Environmental Management Group: Biodiversity. http://www.uneng. org/meetingsdocuments/issuemanagementgroup/biodiversity/tabid/6278/default.aspx

Uwakwe, F.E and Ehujuo, C.A (2012) Water Education for Sustainable Development in Nigeria. Journal of Educational and Social Research. Vol. 2 (8) pp128-138.

Uwakwe, F.E. and I wuala, M.O.E (2012) Studies on the characteristics and Public Health Implications of Waste Dumpsites in Owerri, Imo State, Nigeria. International J ournal for Environmental Health and Human Development. Vol. 3 (2) pp. 1-11.

Wikipedia (2013) Developing Countries.enwikipedia.org/../developing - country.

Wikipedia(2012). Environment management. Enwikipedia.org/wiki/environmental-management. 